\title{
DISTRIBUIÇÃO DO VERDE
}

\author{
Marcelo Reis Savergnini Maia ${ }^{1}$
}

\author{
Anne Elly Pereira Fonseca ${ }^{2}$
}

Natacha Silva Araújo Rena ${ }^{3}$

\begin{abstract}
RESUMO
Inicialmente apresentamos uma análise crítica de como a construção das cidades modernas ao longo do século XIX e XX lidou com a natureza do ponto de vista social, cultural e cotidiano. Partindo de reflexões de Carolyn Steel (2013) que nos fala da emancipação da cidade da natureza e de seus ciclos, passando pela sentimentalização da natureza descrita por Jane Jacobs (2000), propomos uma forma de ver o ambiente urbano como continuidade da natureza. Num segundo momento, buscamos verificar como a natureza faz parte do desenho de algumas cidades escolhidas para observarmos principalmente o aspecto cultural e acesso/uso cotidiano. Como suporte de análise e discussão deste trabalho, desenvolvemos diagramas que, a partir de alguns critérios específicos permitiram visualizar e discutir como o verde é distribuído nas cidades analisadas e quais são suas implicações para o ambiente urbano e para o cotidiano de seus moradores.
\end{abstract}

PALAVRAS-CHAVE: natureza urbana, distribuição do verde, compartilhamento e distribuição do comum, ambiente urbano, cidades verdes.

\section{GREEN DISTRIBUTION}

\begin{abstract}
Initially we present a critical analysis of how the construction of modern cities throughout the nineteenth and twentieth century dealt with the nature from the social, cultural and everyday life. Based on reflections of Carolyn Steel (2013), that tells us about city emancipation of the nature and its cycles, through sentimentalization of nature described by Jane Jacobs (2000), we propose a vision of

\footnotetext{
${ }^{1}$ Arquiteto Urbanista, Doutor em Arquitetura e Urbanismo, Professor do Departamento de Urbanismo da Escola de Arquitetura da UFMG. marcelo.maia@gmail.com.

${ }_{2}^{2}$ Estudante de Arquitetura e Urbanismo, Escola de Arquitetura da UFMG. annefonseca83@gmail.com

${ }^{3}$ Arquiteta Urbanista, Doutora em Comunicação e Semiótica, Professora do Departamento de Análise Crítica da Escola de Arquitetura da UFMG, natacharena@gmail.com
} 
nature in contemporary cities. Secondly, we seek to ascertain how the nature is part of the design of some cities chosen as a case study to primarily observe the cultural aspect and access/daily use of its nature resources. In specific case, we observed the green areas of cities. To support analysis and discussion of this work, we developed diagrams from some specific criteria that allows you to view and discuss and how green areas are distributed in these cities and what are their implications for the urban environment and the daily lives of its residents.

\section{DISTRIBUCIÓN VERDE}

\section{RESUMEN}

Inicialmente se presenta un análisis crítico de la forma en la construcción de las ciudades modernas durante todo el siglo XIX y XX, se ocupó de la naturaleza del punto de vista social, cultural y de la vida cotidiana. Sobre la base de las reflexiones de Carolyn Steel (2013), Emancipación ciudad nos habla de la naturaleza y sus ciclos, a través sentimentalización de la naturaleza descrita por Jane Jacobs (2000), se propone una visión de la naturaleza urbana en las ciudades contemporáneas. En segundo lugar, se busca determinar cómo la naturaleza es parte del diseño de algunas ciudades elegidas como caso de estudio para observar principalmente el aspecto cultural y el acceso/uso diario. En el caso concreto, vemos las áreas verdes de las ciudades. Para apoyar el análisis y la discusión de este trabajo, hemos desarrollado diagramas de algunos criterios específicos le permite ver y discutir y lo verde que se distribuyen en estas ciudades y cuáles son sus consecuencias para el medio ambiente urbano y la vida cotidiana de los residentes.

\section{INTRODUÇÃO}

Carolyn Steel (2013) relata com precisão o processo histórico que culminou na emancipação do cotidiano urbano de qualquer relação direta com a natureza. Analisando a relação entre alimentação e a vida cotidiana, Steel descreve como as relações sociais cotidianas do sistema, incluso as familiares e afetivas, se constituíram na dependência dos ciclos naturais de produção e comercialização dos alimentos. Numa retrospectiva histórica, Steel mostra como a modernização das cidades foi deshumanizando essa relação e causando prejuízos à vida humana ao longo do século XX. Neste processo emancipatório, nossa relação com a alimentação, e consequentemente com a natureza, que é quem nos fornece o alimento essencial à vida, tornou-se mecanizado e, mais recentemente, automatizado. Assim, o que antes era o centro da vida familiar, comunitária e urbana, torna-se periférico e com altos prejuízos tanto à natureza quanto à saúde. 
Hoje para conseguir comida, entramos em nossos carros e dirigimos até um supermercado onde levamos comida o suficiente para encher nossa geladeira e dispensa por uma semana ou mais. A comida que costumava ser o centro, o núcleo social nas primeiras aglomerações humanas, agora está na periferia, num supermercado, num shopping qualquer. Antes era um evento social, comprar e vender comida nas feiras, e agora, não passa de um processo anônimo e tão automatizado, que serviços de venda de alimentos online com entrega à domicílio parecem ser tão óbvios e práticos que nos perguntamos porque não existiam antes. Tudo tende à um instantâneo - plantar, colher, preparar, comercializar, negociar, comprar, preparar, cozinhar, assentar-se à mesa e compartilhar o alimento - todos estes processos listados cabem num pacote de papel que nós tiramos da dispensa, derramamos numa travessa, adicionamos água quente, misturamos e pronto! A quantidade de processos econômicos, culturais, sociais e afetivos que foi suprimido do cotidiano neste sistema que acabamos de descrever é considerável. Observe que não estamos falando aqui de uma relação saudosista antiurbana e romântica, mesmo porque, como vimos em Lefebvre, o urbano é um processo contínuo de transformação de uma sociedade construída pelo processo de industrialização que domina e absorve a produção agrícola (LEFEBVRE, 1999). O que estamos chamando atenção é o quanto este processo de urbanização conquistou, efetivamente nos séculos XIX e XX, a emancipação da cidade, por exemplo, dos ciclos naturais de produção de alimentos na industria alimentícia e da alternância noite e dia com a energia elétrica.

Os seres humanos fazem parte da natureza e sendo o produto de uma forma de natureza, as cidades dos seres humanos são tão naturais quanto qualquer outro ambiente (JACOBS, 2000). A separação ambiente urbano e ambientes natural se desdobrou num processo de sentimentalização onde a natureza é admirada e ao mesmo tempo, segundo Jacobs (2000, p. 495), é objeto de um profundo descaso inconsciente. Quando pensamos em natureza numa perspectiva urbana, logo pensamos em pedaços reservados para tal função, assim como se desenvolveu todas as soluções para os problemas das cidades no mundo moderno. Uma simplificação de funções e variáveis onde partes se organizam de modo funcional, 
como uma máquina. Assim como Jacobs, Simmel já alertava que "um pedaço de natureza é uma contradição; a natureza não tem fracções; é a unidade de um todo, e no momento em que dela se aparta deixará de ser natureza" (SIMMEL, 2009, p.6). Logo, se separamos a cidade da natureza, estamos falando de um ambiente totalmente artificial, ou em outras palavras, sem vida. Cidades sem vida, ou cidades mortas são possíveis? Acreditamos que não, mas quando há uma intenção em separá-la, acaba-se por criar um espaço onde os problemas são ordenados de forma simplificada e protegidos dentro de um ambiente artificialmente esterilizado. Um exemplo desta possibilidade é a criação em proporções sem precedentes de réplicas de cidades inteiras na China, atualmente conhecidas como Ghost Cities of China, sem moradores, anunciando um colapso em cascata do sistema de commodities do mercado financeiro mundial (SHEPARD, 2015, loc.183). Estas réplicas sem vida, foram projetadas por designers, urbanistas, arquitetos e engenheiros que nunca estiveram na China (SHEPARD, 2015, loc.162). Ao alcançar o extremo da simplificação das variáveis naturais de uma cidade, possibilitou que no início do século $\mathrm{XXI}$, conseguíssemos construir cidades sem habitantes. Estas sim, em oposição às cidades vivas de Jacobs e naturais de Simmel.

Entender o ambiente urbano como natureza, permite perceber que o consumo de recursos naturais para se manter a cidade não ocorre de modo independente e desconectado dos sistemas naturais. A cidade não é uma bolha à parte da natureza. Hoje, os campos de soja no interior do Mato Grosso e as novas usinas hidroelétricas no norte do Brasil que se impõe sobre a floresta amazônica é um desdobramento direto das infraestruturas conectadas diretamente com redes de cidades em uma escala global. Monte-Mór (1994, p.171) nos mostra este processo ao falar de "uma urbanização extensiva que se estende para além das cidades em redes que penetram virtualmente todos os espaços regionais integrando-os em malhas mundiais". Trata-se de uma rede complexa e distribuída de fluxos de recursos que alimentam um sistema dinâmico que é o processo de urbanização. Desde então, temos procurado observar e entender o urbano como natureza e ao mesmo tempo entender o quanto a natureza invade os planos urbanos simplificados criando condições de vida saudáveis e sustentáveis. 
Inicialmente, motivados pelos índices de área verde por habitante, que são constantemente divulgados pelas prefeituras como forma de anunciar uma certa qualidade de vida dos ambientes urbanos por elas administrados, passamos a observar como as áreas verdes são distribuídas dentro do tecido urbano de algumas cidades. Assim como os sistemas naturais se interconectam e interrelacionam dinamicamente, e entendendo que o ambiente urbano é natureza, procuramos identificar uma topologia de rede (verde) distribuída no tecido urbano.

\section{OBJETIVOS}

Escolhemos aleatoriamente, algumas cidades brasileiras para este estudo e a cidade eleita em 2014 pela Comissão Européia como a mais verde da Europa (EC, 2012). Não é objetivo desde estudo apresentar uma análise técnica ou estatística da distribuição do verde nas cidades brasileiras nem tampouco comparar a nossa experiência com a européia. Inicialmente é nosso objetivo criar um instrumento gráfico de visualização que suscite questões e estabeleça uma conversa. Questões que poderão se desdobrar em novas frentes de pesquisa considerando o ambiente urbano como natureza. Logo, estabelecemos como objetivos específicos deste estudo:

- Criar um modelo de visualização gráfica que permita observar criticamente e estabelecer um diálogo sobre a topologia do verde na cidade;

- tendo em mãos o instrumento de visualização gráfico criado (diagramas), iniciar uma análise preliminar, visual, da distribuição do verde nas cidades.

Ainda em tempo, objetivamos analisar o verde na cidade de um ponto de vista menos quantitativo e mais qualitativo. Observar o verde enquanto parte do tecido urbano e não apenas como uma porção de natureza dentro de um plano urbanístico.

Entende-se o distribuído como algo descentralizado, imediatamente acessível e diretamente conectado. Ou seja, é objetivo perceber o quanto as nossas cidades estão diretamente conectadas com suas áreas verdes e o quanto a natureza 
é colocada à parte da cidade. Mesmo que a presença da natureza seja intensa do ponto de vista paisagístico, ela nem sempre está distribuída; ou seja, imediatamente acessível e conectada à vida cotidiana de seus moradores.

\section{METODOLOGIA}

Construímos gráficos destacando o que é superfície verde no tecido urbano tendo como base fotos de satélite. Estes gráficos partem de uma base informacional cartográfica e são acrescidos de apostas que criam uma camada informacional que contrapõe a informação dada. Este método, também conhecido por diagramas, permite construir imagens que sensibilizam a informação, sugerindo uma análise cruzada de informações num instrumento visual. Ao utilizar diagramas como método, estamos criando formas de visualização de uma situação sem compromisso com dados ou rigor técnico. Logo, não estamos fazendo um levantamento técnico estatístico, mas muito mais um procedimento artístico e aberto de produção de base informacional que suscite questões e estabeleça a possibilidade de uma conversa sobre o tema.

\section{MÉTODO DE ANÁLISE}

Para a construção dos diagramas adotamos os seguintes procedimentos:

1. Delimitação de um recorte da foto de satélite aproximadamente $10.000 \mathrm{~m}$ $x 7.000 \mathrm{~m}$ tendo como foco a região central de 4 cidades brasileiras e 1 européia: Rio de Janeiro, Belo Horizonte, Curitiba, Brasília e Copenhague.

2. Através da edição das imagens, destacamos toda a superfície verde da malha urbana tais como áreas residuais, quintais, lotes, praças, parques, APPs (áreas de preservação permanente), etc., assim, o que é de cor verde foi, destacado com a cor preta, e o restante das cores da imagem são apuradas como de cor branca. Nesta construção gráfica, 
imediatamente percebemos intensidades deste verde, manchas mais escuras com alta densidade e mais claras com pouca densidade.

3. Em seguida, identificamos as áreas que são significativamente negras no mapa, portanto de maior importância. Destas, separamos as áreas que possuem livre acesso, sejam elas públicas ou privadas.

4. Por fim, traçado um raio de $1,5 \mathrm{~km}$ partindo de um ponto central quando a área verde for aberta para a malha urbana, ou de sua entrada principal quando a área verde for cercada, desenhamos uma circunferência verde.

Imediatamente geramos dois diagramas, um que permite a leitura do verde na malha urbana identificando visualmente a quantidade, densidade $e$ permeabilidade do verde na malha. Um segundo onde predomina camadas de circunferências verdes para cada ponto de acesso cotidiano ao verde, que permite perceber a forma de distribuição destas áreas na malha, bem como a intensidade de suas conexões. Colocando os digramas de diversas cidades lado a lado, podemos rapidamente comparar suas diferenças, similaridades e características peculiares.

\section{RESULTADOS}

Apresentaremos a seguir uma sequência de diagramas, dois para cada uma das cidades escolhidas deste estudo. O primeiro diagrama de cada cidade, refere-se às áreas verdes identificadas na malha urbana destacas em preto, onde podemos observar a intensidade e as características da sua distribuição na malha urbana. Pequenos círculos verdes, marcam o ponto de acesso livre de áreas verdes significativas, quer sejam elas públicas ou privadas. Estas áreas foram destacadas por seu uso cotidiano ou inserção prática na malha urbana. Logo, grandes áreas verdes, sem acesso livre, ou áreas verdes residuais, que não possuem apropriação ou uso cotidiano não foram destacados. O segundo diagrama, desenha um raio de $1,5 \mathrm{~km}$ do centro de cada ponto marcado no primeiro diagrama. Deste modo, podese perceber a amplitude deste verde que é parte do cotidiano da cidade, e que está a uma distância de aproximadamente 30 minutos de caminhada. 


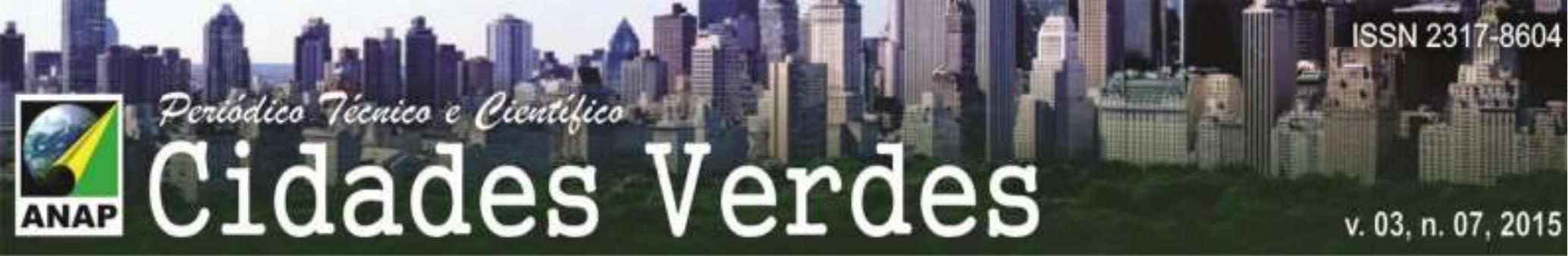

Figura 1: Recorte do Rio de Janeiro. Fonte: Edição do autor sobre Google Imagens, 2015.

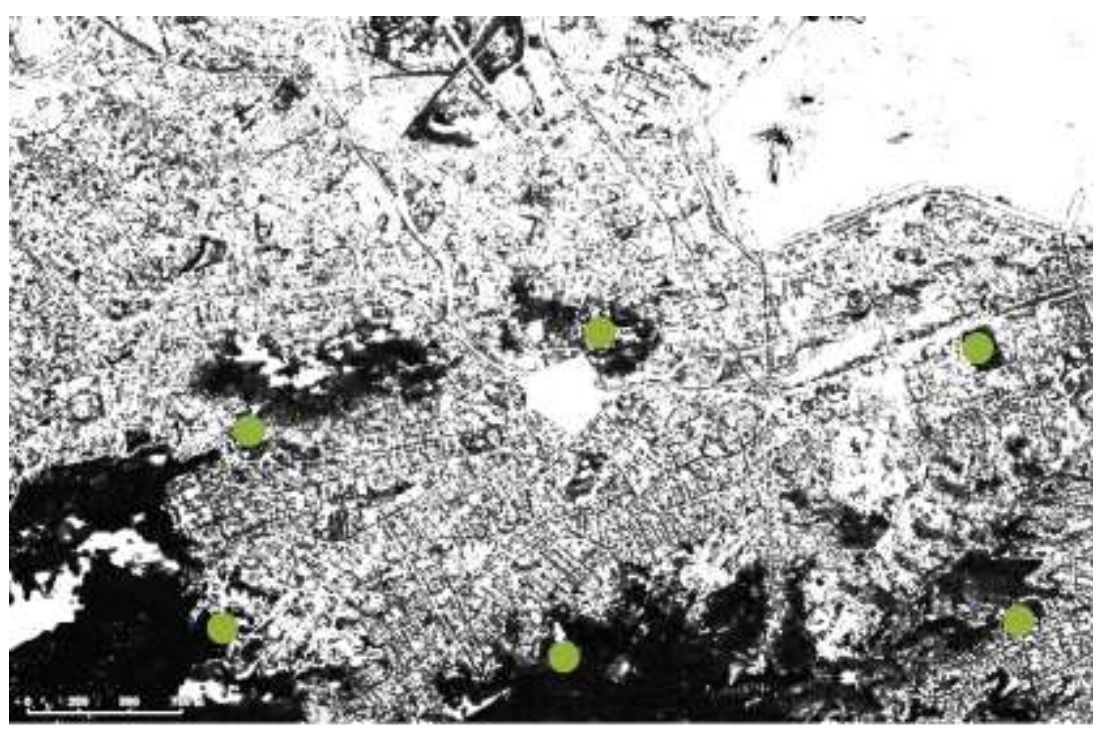

[ [AREAS VERDES DE ACESSO PÜBLLCO]

Figura 2: Recorte do Rio de Janeiro. Fonte: Edição do autor sobre Google Imagens, 2015.

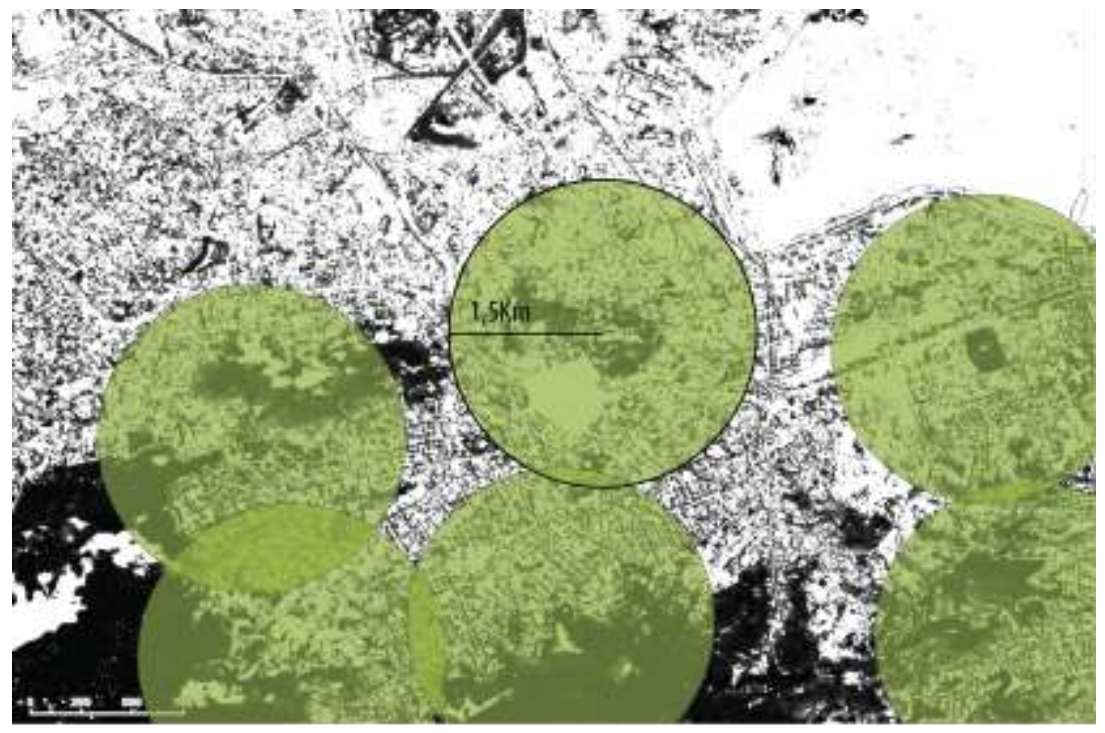

[ CONECTIVIDADE ENTRE ÁREAS VERDES - RAIO DE 1,5Km ] 
central apresentam aspectos semelhantes no que diz respeito à quantidade de área verde, seu uso e sua distribuição. Ambas imagens apresentam avantajadas manchas de áreas verde que compreendem o Parque Nacional da Tijuca e o Parque Municipal das Mangabeiras, respectivamente. São reservas concentradas em uma determinada região da cidade com dinâmicas espaciais independentes do cotidiano urbano em que estão inseridos. No Rio de Janeiro, o recorte encerrou a face norte do Parque Nacional da Tijuca, abrangendo o centro e o porto, deixando a área que está entre o mar e o Parque fora do diagrama. Esta área, dado a presença do mar, apresenta uma ambiente com características distintas, que por sua vez, exigiria outros procedimentos para os métodos de análise.

É possível averiguar que grande parte dos recortes das duas cidades apresenta uma malha clara e pouco expressiva de arborização viária.

Curitiba (figuras 5 e 6) possui manchas de áreas verdes de acesso público significativas inseridas no contexto urbano, além de uma arborização viária mais densa, possui vários pontos de acesso e conexão destas áreas possibilitando uma inserção do verde no cotidiano de modo mais fluido do que podemos ver nas duas últimas cidades.

O Plano Piloto de Brasília (figuras 7 e 8) institui um aspecto particular de acesso público às áreas livres: as superquadras. A superquadra é uma forma de implantação que valoriza a escala humana de mobilidade e conforto ambiental correspondentes às duas asas do plano. São quadras abertas cuja implantação dos edifícios residenciais se dá sobre pilotis envoltos por áreas generosamente arborizadas, que configuram uma forma inusitada de utilização do solo e uma relação mais democrática dos cidadãos para com os espaços livres. As superquadras articulam-se linearmente entre si, e com o Parque da Cidade na Asa Sul, conformando a continuidade desses espaços.

Uma relação inversa ocorre para a escala do Eixo Monumental, que legitima o caráter de capital federal, cujas áreas verdes são colossais na paisagem. A escala é compatível com a velocidade do carro, de caráter contemplativo. 
Em 2014, Copenhague foi eleita pela Comissão Européia como a cidade mais verde da Europa $^{4}$ (EC, 2012). A imagem da cidades de Copenhague (figuras 9 e 10) apresenta malha substancialmente arborizada quando comparadas com as demais cidades abordadas. É ainda mais significante a densidade de áreas verdes de acesso público, e o resultado do lançamento do raio de 1,5km é a interceção quase completa de todo o recorte da cidade. Ao aproxima e entender como a natureza é desenhada na cidade, percebemos planos e políticas voltadas para uma rede de cemitérios tratados como oásis, casas de cultivo agrícola, escolas de jardinagem e uma comunidade de produção e distribuição de alimentos orgânicos produzidos localmente [5]. A natureza é inserida no cotidiano da cidade de tal forma que atravessa não apenas todas as quadras, assim como as superquadras em Brasília, mas também a vida de seus habitantes. O lazer, o consumo de alimentos, a mobilidade, a socialização estão diretamente conectados e interdependes desta natureza que se infiltra no desenho da cidade e de seus edifícios. Ainda como plano de desenvolvimento metropolitano, Copenhague expande-se em direção a cinco vetores equidistantes, percebidos em plano como dedos de uma mão aberta, onde o espaço entre os dedos necessariamente é destinado a áreas verdes. A complexidade do desenho da cidade e suas múltiplas variáveis interrelacionadas são reveladas na agenda de Copenhague ao tratar do verde que incorpora a natureza nos planos de transporte local, biodiversidade, uso sustentável de áreas verdes, poluição sonora, manejo do lixo, tratamento de água e esgoto, performance energética, entre outros explicitados nos relatórios enviados à Comissão Européia (EC, 2014).

\footnotetext{
${ }^{4}$ Sobre os lugares verdes e o compartilhamento de suas áreas verdes comuns buscamos informações nas páginas institucionais do Sharing Copenhagen disponível em: $<\mathrm{http}: / /$ www.sharingcopenhagen.dk/english/green-tours/green-places/?category=2647> Acesso em: 29/05/2015.
} 


\section{REFERÊNCIAS}

EC, European Comission. European Green Capital: Copenhagen Green Urban Areas. Copenhagen, EC, 2012. disponível em: <http://ec.europa.eu/environment/europeangreencapital/wpcontent/uploads/2012/07/Section-3-green-urban-areas_Copenhagen.pdf> acesso em: 29/05/2015.

EC, European Comission. Copenhagen Application. Copenhagen, EC, 2014. disponível em: <http://ec.europa.eu/environment/europeangreencapital/winning-cities/2014-

copenhagen/copenhagen-application/index.html> acesso em: 29/05/2015.

INDISCIPLINAR. Compartilhamento e Distribuição do Comum. Wiki Indisciplinar, UFMG, Belo Horizonte, 2015.2 disponível em: <http://wiki.indisciplinar.com/index.php?title=Compartilhamento_e_Distribui\%C3\%A7\%C3\%A3o_do_C omum> acesso em 29/05/2015.

INDISCIPLINAR. Rede Verde. Wiki Indisciplinar, UFMG, Belo Horizonte, 2015. disponível em: <http://wiki.indisciplinar.com/index.php?title=Rede_Verde> acesso em 29/05/2015.

JACOBS, Jane. Morte e Vida de Grandes Cidades. Martins Fontes Editora, São Paulo, 2000.

LEFEBVRE, Henri. A Revolução Urbana. Belo Horizonte: Ed. UFMG, 1999.

MAIA, Marcelo Reis. Cidade instantânea (IC). 2013. Tese (Doutorado em Design e Arquitetura) Faculdade de Arquitetura e Urbanismo, Universidade de São Paulo, São Paulo, 2013. Disponível em: $<$ http://www.teses.usp.br/teses/disponiveis/16/16134/tde-03072013-162823/>. Acesso em: 2014-0616.

MONTE-MÓR, Roberto Luís de M. Urbanização Extensiva e Lógicas de Povoamento: Um Olhar Ambiental. in: SANTOS, Milton et. al. (orgs.) Território, globalização e fragmentação. São Paulo: Hucitec/Anpur, 1994 (pp. 169-181)

RENA, Natacha. Parque Augusta e as resistências verdes. Blog Indisciplinar, UFMG, Belo Horizonte, 2014. disponível em: <http://wiki.indisciplinar.com/index.php?title=Rede_Verde> acesso em 29/05/2015.

SHEPARD, Wade. Ghost Cities of China: The Story of Cities Without People in The World's Most Populated Country. Zed Books, London, 2015. Kindle Edition.

SIMMEL, George. A Filosofia da Paisagem. Universidade da Beira Interior Covilhã, 2009.

STEEL, Carolyn. Hungry City: How Food Shapes Our Lives. Vintage Publishing, London, 2013. 